\title{
A Recent Expansion of the RXLR Effector Gene Avrblb2 Is Maintained in Global Populations of Phytophthora infestans Indicating Different Contributions to Virulence
}

\author{
Ricardo F. Oliva, ${ }^{1}$ Liliana M. Cano, ${ }^{1}$ Sylvain Raffaele, ${ }^{1}$ Joe Win, ${ }^{1}$ Tolga O. Bozkurt, ${ }^{1}$ \\ Khaoula Belhaj, ${ }^{1}$ Sang-Keun Oh, ${ }^{2}$ Marco Thines, ${ }^{3,4,5}$ and Sophien Kamoun' \\ ${ }^{1}$ The Sainsbury Laboratory, Norwich Research Park, Norwich, NR4 7UH, United Kingdom; ${ }^{2}$ Plant Genomics and \\ Breeding Institute, Seoul National University, Seoul 151-742, Korea; ${ }^{3}$ Biodiversity and Climate Research Centre BiK-F, \\ Senckenberganlage 25, D-60325 Frankfurt (Main), Germany; ${ }^{4}$ Goethe University, Department of Biological Sciences, \\ Institute of Ecology, Evolution and Diversity, Siesmayer. 70, D-60323 Frankfurt (Main), Germany; ${ }^{5}$ Senckenberg \\ Gesellschft für Naturforschung, Senckenbergallee 25, D-60325 Frankfurt (Main), Germany
}

Submitted 11 April 2015. Accepted 13 April 2015.

\begin{abstract}
The introgression of disease resistance $(R)$ genes encoding immunoreceptors with broad-spectrum recognition into cultivated potato appears to be the most promising approach to achieve sustainable management of late blight caused by the oomycete pathogen Phytophthora infestans. Rpi-blb2 from Solanum bulbocastanum shows great potential for use in agriculture based on preliminary potato disease trials. Rpi-blb2 confers immunity by recognizing the $P$. infestans avirulence effector protein AVRblb2 after it is translocated inside the plant cell. This effector belongs to the RXLR class of effectors and is under strong positive selection. Structure-function analyses revealed a key polymorphic amino acid (position 69) in AVRblb2 effector that is critical for activation of Rpi-blb2. In this study, we reconstructed the evolutionary history of the Avrblb2 gene family and further characterized its genetic structure in worldwide populations. Our data indicate that Avrblb2 evolved as a single-copy gene in a putative ancestral species of $P$. infestans and has recently expanded in the Phytophthora spp. that infect solanaceous hosts. As a consequence, at least four variants of AVRblb2 arose in $P$. infestans. One of these variants, with a Phe residue at position 69, evades recognition by the cognate resistance gene. Surprisingly, all Avrblb2 variants are maintained in pathogen populations. This suggests a potential benefit for the pathogen in preserving duplicated versions of AVRblb2, possibly because the variants may have different contributions to pathogen fitness in a diversified solanaceous host environment.
\end{abstract}

Current address of R. Oliva: International Rice Research Institute, DAPO 7777, Los Baños, Philippines.

Current address of S. Raffaele: Institut National de la Recherche Agronomique, Laboratoire des Interactions Plantes-Microorganismes, Unité Mixte de Recherche 441, F-31326 Castanet-Tolosan, France.

Current address of L. M. Cano: North Carolina State University, Department of Plant Pathology, Raleigh 27695, U.S.A.

Corresponding author: S. Kamoun; E-mail: sophien.kamoun@tsl.ac.uk

*The $\boldsymbol{e}$-Xtra logo stands for "electronic extra" and indicates that two supplementary figures and seven supplementary tables are published online.

(c) 2015 The American Phytopathological Society
In order to colonize plants, many pathogens rely on the secretion of effector molecules that suppress host defenses and facilitate colonization (Jones and Dangl 2006; Hogenhout et al. 2009; Win et al. 2012a). However, in plants that carry resistance $(R)$ genes, disease progression is prevented when the corresponding effector is perceived either directly or indirectly (van der Hoorn and Kamoun 2008). This immunoreceptor-mediated recognition triggers an overall defense reaction, termed effectortriggered immunity (ETI), which culminates in a form of programmed cell death called the hypersensitive response. In response, plant pathogens have evolved different molecular mechanisms to evade or inactivate ETI while maintaining overall fitness. This battle between plant and pathogen is a driving force in creating and maintaining genetic diversity in pathogen effectors and plant $R$ genes (McDonald and Linde 2002). The resulting evolutionary dynamics have most likely contributed to shaping the distinctive genome architecture of many plant pathogens (Croll and McDonald 2012; Raffaele and Kamoun 2012), and continue to drive pathogen evolution in managed ecosystems (Vleeshouwers et al. 2011; Yoshida et al. 2013). Therefore, understanding the distribution of effector diversity in agricultural systems has practical applications for disease management strategies and for the deployment of disease resistant crop varieties.

The oomycete Phytophthora infestans is the causal agent of late blight, by far the most devastating disease of potato (Solanum tuberosum) worldwide (Kamoun et al. 2015). The pathogen originated in central Mexico and clusters in the Phytophthora clade 1c together with three other North American species: P. ipomoeae, P. mirabilis, and P. phaseoli (Blair et al. 2008; Goss et al. 2014; Martin et al. 2014). These clade 1c species evolved through host jumps followed by adaptive specialization on plants belonging to four different botanical families (Dong et al. 2014; Grünwald and Flier 2005; Raffaele et al. 2010). In South America, the Andean species $P$. andina occurs on Solanum spp. and has emerged though hybridization between $P$. infestans and an unknown Phytophthora sp. (Goss et al. 2011, 2014).

The genomes of several species in clade 1c have been resequenced and compared with the genome of a reference strain of $P$. infestans (Haas et al. 2009; Raffaele et al. 2010). Compared with other Phytophthora spp. such as $P$. ramorum and $P$. sojae, members of Phytophthora clade 1c have large (approximately 220 to $280 \mathrm{Mbp}$ ) genomes with dramatic repeat-driven expansions interspersed 
between gene-dense and repeat-poor regions (Haas et al. 2009). This peculiar genome structure, termed a two-speed genome architecture, is thought to have enabled pathogen adaptability and, therefore, has important implications for management strategies of the late blight disease (Raffaele and Kamoun 2012; Vleeshouwers et al. 2011).

Although late blight disease can be managed by chemical application, the most promising approach to achieve sustainable management is the introgression of $R$ genes with broad-spectrum pathogen recognition from wild Solanum germplasm (Park et al. 2009; Vleeshouwers et al. 2011). Several $R$ genes that confer resistance to late blight have been cloned from wild relatives of potato (Ballvora et al. 2002; Foster et al. 2009; Huang et al. 2005; Li et al. 2011; Lokossou et al. 2009; Song et al. 2003; van der Vossen et al. 2003, 2005). All encode putative cytoplasmic nucleotide-binding leucine-rich repeat (NB-LRR) proteins, a major class of plant immunoreceptors (Jacob et al. 2013; Mukhtar 2013). To date, the Mexican wild species $S$. bulbocastanum has been the most significant source of broad-spectrum late blight resistance (Vleeshouwers et al. 2011). Two S. bulbocastanum genes, Rpi-blbl and Rpi-blb2, are effective against the majority of tested isolates of $P$. infestans (Champouret et al. 2009; Song et al. 2003; van der Vossen et al. 2003, 2005). This observation has motivated several initiatives to deploy Rpi-blbl and Rpi-blb2 in agricultural ecosystems by conventional breeding or biotechnological approaches (Vleeshouwers et al. 2011).

Similar to other plant pathogens, $P$. infestans secretes a diverse arsenal of host-translocated effectors that modulate plant immunity (Kamoun 2003; Morgan and Kamoun 2007). Defined by a conserved N-terminal motif, the RXLR type of effectors represents a highly diverse family encoded by approximately 550 predicted genes in the genomes of $P$. infestans and related species, and approximately 300 in other Phytophthora spp. (Haas et al. 2009; Tyler et al. 2006). A subset of $P$. infestans RXLR effectors are recognized by NB-LRR receptors and are then said to have an avirulence activity (i.e., trigger ETI). The first $P$. infestans avirulence effector to be described is AVR3a, which confers avirulence on potato plants carrying the cognate immune receptor $S$. demissum R3a (Armstrong et al. 2005; Bos et al. 2006). Other P. infestans RXLR effectors with known avirulence activity are AVR1, AVR2, AVR4, AVRblb1, AVRblb2, AVRvnt1, and AVRSmira2 which activate the NB-LRR immune receptors R1, R2, R4, Rpiblb1, Rpi-blb2, Rpi-vnt1.1, and Rpi-Smira2, respectively (Gilroy et al. 2011; Oh et al. 2009; Pel 2010; Rietman et al. 2012; van Poppel et al. 2008; Vleeshouwers et al. 2008).

Virulent strains of $P$. infestans that evade recognition by $R$ genes may carry nonsynonymous or frameshift mutations in particular avirulence effector genes, as is the case for Avr $3 a$ and Avr4, respectively (Bos et al. 2006; van Poppel et al. 2008). Transcriptional silencing is another mechanism associated with gain of virulence, as observed for several $P$. sojae avirulence effector genes (Dong et al. 2009; Qutob et al. 2009). A P. infestans strain that colonizes plants carrying the Rpi-vnt1.1 gene showed no detectable Avrvnt1 transcripts during the biotrophic phase, although the gene sequence remained intact (Pel 2010). P. infestans can also evolve multiple mechanisms to escape recognition by a given $R$ gene. $P$. infestans strains that are virulent on $R 2$ potato plants may display deletion, sequence polymorphism, or transcriptional silencing of the cognate Avr2 gene (Gilroy et al. 2011). Some effector proteins can inhibit the elicitation produced by other family members. Physical interaction of $P$. infestans virulent effector IPI-O4 disrupts the activation of Rpi-blb1 by the avirulent allele IPI-O1 (Chen et al. 2012).

AVRblb2 is a small RXLR-type effector protein that is specifically recognized by the resistance protein Rpi-blb2 (Oh et al. 2009). The 100-amino-acid (aa) AVRblb2 is highly polymorphic and appears to be under diversifying selection in $P$. infestans $(\mathrm{Oh}$ et al. 2009). The small 50-aa C-terminal effector domain of
AVRblb2 is sufficient for activating Rpi-blb2 and appears unrelated to the WY domain that was detected in AVR3a and approximately $44 \%$ of Phytophthora RXLR effectors (Boutemy et al. 2011; Win et al. 2012b). Structure-function experiments indicated that a 34-aa region in the C-terminal half of AVRblb2 is sufficient for triggering Rpi-blb2 hypersensitivity (Oh et al. 2009). Oh et al. (2009) also identified a functionally critical residue at position 69 with four natural amino acid position variants: Alanine (Ala-69), Valine (Val-69), Isoleucine (Ile-69), and Phenylalanine (Phe-69). Among them, Phe-69 compromises the activation of Rpi-blb2, suggesting that it may have evolved to escape $R$-gene-mediated recognition. To date, virulent strains that fully overcome Rpi-blb2 resistance gene have not been described in the literature, prompting us to explore in detail the population genetics of Avrblb2 effector (Vleeshouwers et al. 2011).

The deployment of an $R$ gene in agriculture often triggers rapid changes in pathogen populations (McDonald and Linde 2002; Yoshida et al. 2013). Virulent races of oomycete and fungal pathogens are frequently detected soon after the deployment of $R$ genes (Fry 2008; Takken and Rep 2010). Given that potato varieties carrying Rpi-blb2 are expected to be deployed in the coming years, we decided to obtain an overview of Avrblb2 diversity prior to exposure of the pathogen to the corresponding $R$ gene. The work was facilitated by the prior identification of nonsynonymous substitutions at amino acid position 69 at the C-terminal effector domain of AVRblb2 as key determinants of recognition by Rpi-blb2. The prediction that strains that lack the Avrblb2 gene are homozygous for Phe-69 also suggests that could become virulent on Rpi-blb2 potatoes (Oh et al. 2009). In this study, we investigated the structure and evolution of the Avrblb2 loci within Phytophthora clade 1c species. We developed functional markers to access the composition of AVRblb2 effector variants in a $P$. infestans metapopulation. We hope this study can be used as a baseline for future monitoring of the emergence of virulent races that may accompany the agricultural deployment of Rpi-blb2.

\section{RESULTS}

\section{Genome organization of the Avrblb2 effector family in $P$. infestans T30-4.}

According to Haas et al. (2009), Avrblb2 occurs as a family of seven paralogs (PITG_04085, PITG_04086, PITG_04090, PITG_18683,PITG_20300,PITG_20301, and PITG_20303) in the genome of $P$. infestans T30-4. They share $>90 \%$ amino acid similarity to each other and to PexRD40 ${ }_{170-7}$, described earlier from P. infestans isolate 88069 (Bozkurt et al. 2011; Oh et al. 2009). Sequence alignment of the seven proteins identified 15 variable residues (Fig. 1A). The $P$. infestans genome has an unusual discontinuous distribution of gene density, with effector genes typically localizing to expanded, repeat-rich and gene-sparse regions (GSR) of the genome (Haas et al. 2009). We examined the genome organization of the Avrblb2 paralogs in more detail (Fig. 1B). The seven paralogs occur in three clusters in different supercontigs $(1.5,1.79$, and 1.125) that lack collinear (syntenic) regions in the genomes of $P$. sojae and $P$. ramorum, indicating that these regions have expanded in P. infestans (Fig. 1B). Calculations of intergenic region lengths according to the approach of Haas et al. (2009) confirmed that all Avrblb2 paralogs populate regions with low gene density and high repeat content (Fig. 1B). Typically, GSR in the $P$. infestans genome have a median intergenic distance of $3.7 \mathrm{~kb}$ (Haas et al. 2009). The $5^{\prime}$ intergenic border length of Avrblb2 paralogs varied from 0.8 to $44.9 \mathrm{~kb}$ (average $11.9 \mathrm{~kb}$ ), whereas the $3^{\prime}$ intergenic border length varied from 10.9 to $57.5 \mathrm{~kb}$ (average $36.5 \mathrm{~kb}$ ). Interestingly, PITG_04085 and PITG_04086 are closely linked and occur as nearly identical antiparallel copies, with less than $1 \mathrm{~kb}$ separation at the $5^{\prime}$ end (Fig. 1B). 
To confirm the presence and location of all Avrblb2 paralogs and validate the annotations made from the genome sequence assembly, we designed primers to amplify each of the seven loci predicted from the $P$. infestans T30-4 genome (Supplementary Table S1). Primer sequences were selected within a region of $1 \mathrm{~kb}$ upstream and downstream of the predicted open reading frame (ORF). After polymerase chain reaction (PCR) amplification and gel resolution, DNA fragments (ranging from 955 to 2,395 bp) were consistent with expected product sizes. We sequenced these amplicons and identified seven intact ORF, six of which were coding genes (PITG) predicted in the assembly of the $P$. infestans reference strain T30-4 (Haas et al. 2009). Only one amplicon, most closely related to PITG_18683, did not match any of the expected sequences. However, this particular ORF matches the previously reported variant PexRD40b (Oh et al. 2009), suggesting that PITG_18683 is either an allelic variant that differs from the assembled T30-4 haplotype or an additional paralog that was unresolved in the assembly.

\section{Avrblb2 effector is conserved}

in two sister species of $P$. infestans.

Similarity searches with AVRblb2 effector against the sequenced genomes of $P$. capsici, $P$. ramorum, and $P$. sojae failed to reveal significant matches. However, AVRblb2-like sequences could be identified in some of the sister species of $P$. infestans (Raffaele et al. 2010). To reconstruct the evolutionary history of Avrblb2 in the Phytophthora clade 1c (Blair et al. 2008), we amplified Avrblb2 homologs from $P$. infestans (nine strains), $P$. andina (three strains), P. mirabilis (one strain), P. ipomoeae (one strain), and P. phaseoli (one strain) (Table 1). Primers pairs that target the effector nucleotide sequence encoding for the mature protein of Avrblb2 (Oh et al. 2009) were used to amplify genomic DNA from a set of Phytophthora species panel (Table 1). DNA fragments of the expected size were obtained with all $P$. infestans, $P$. andina, and $P$. mirabilis samples, whereas no amplicons could be recovered from $P$. ipomoeae and P. phaseoli (Table 1). Furthermore, we could not find any evidence of Avrblb2 sequences within P. ipomoeae and $P$. phaseoli genome data described by Raffaele et al. (2010) (Supplementary Table S2). Sequence analysis of the resulting amplicons revealed a high level of similarity with Avrblb2 at the nucleotide level, revealing the presence of Avrblb2 homologs in $P$. andina and $P$. mirabilis. To examine sequence polymorphism in the Avrblb2 homologs, we cloned amplicons into the pGEMT-easy vector (Promega Corp., Madison, WI, U.S.A.) and sequenced 12 colonies per amplicon. Using this strategy, we found eight novel nucleotide sequences encoding eight predicted amino acid sequences among $P$. andina and $P$. mirabilis (Supplementary Table S3; Supplementary Fig. S2).

To further determine gene content and identity in the different strains, we performed PCR amplification using the paralogspecific primers described above. The $P$. infestans panel showed the presence or absence polymorphism of Avrblb2 paralogs. Two to seven paralogs could be detected in each strain. Direct sequencing of amplicons confirmed the presence of each corresponding gene (Table 1). Using this PCR-sequencing approach, we confirmed the occurrence of at least four different paralogs in $P$. andina as well (Table 1). The fact that some loci were conserved between different species validates the robustness of this approach. It is likely that most polymorphisms were due to gain or loss of genes; however, mutation at the primer binding sequence could

A

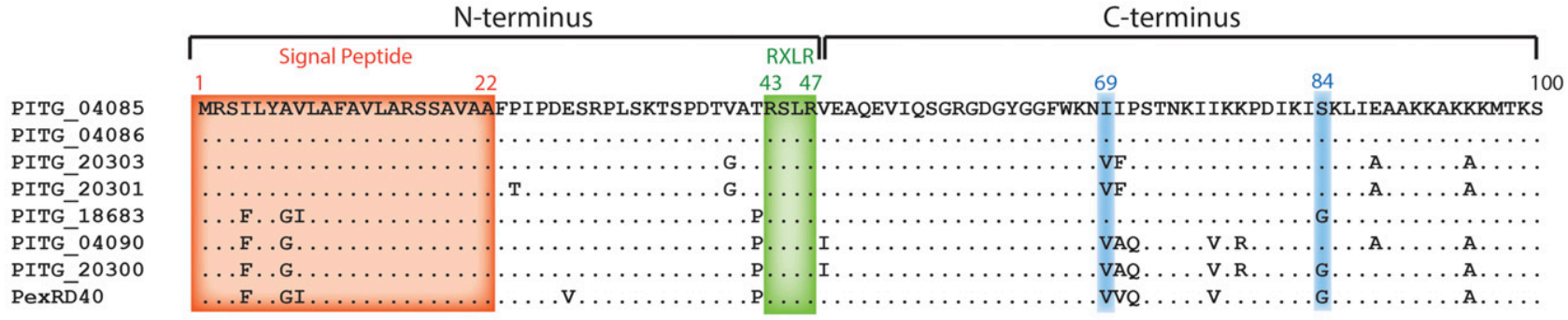

B

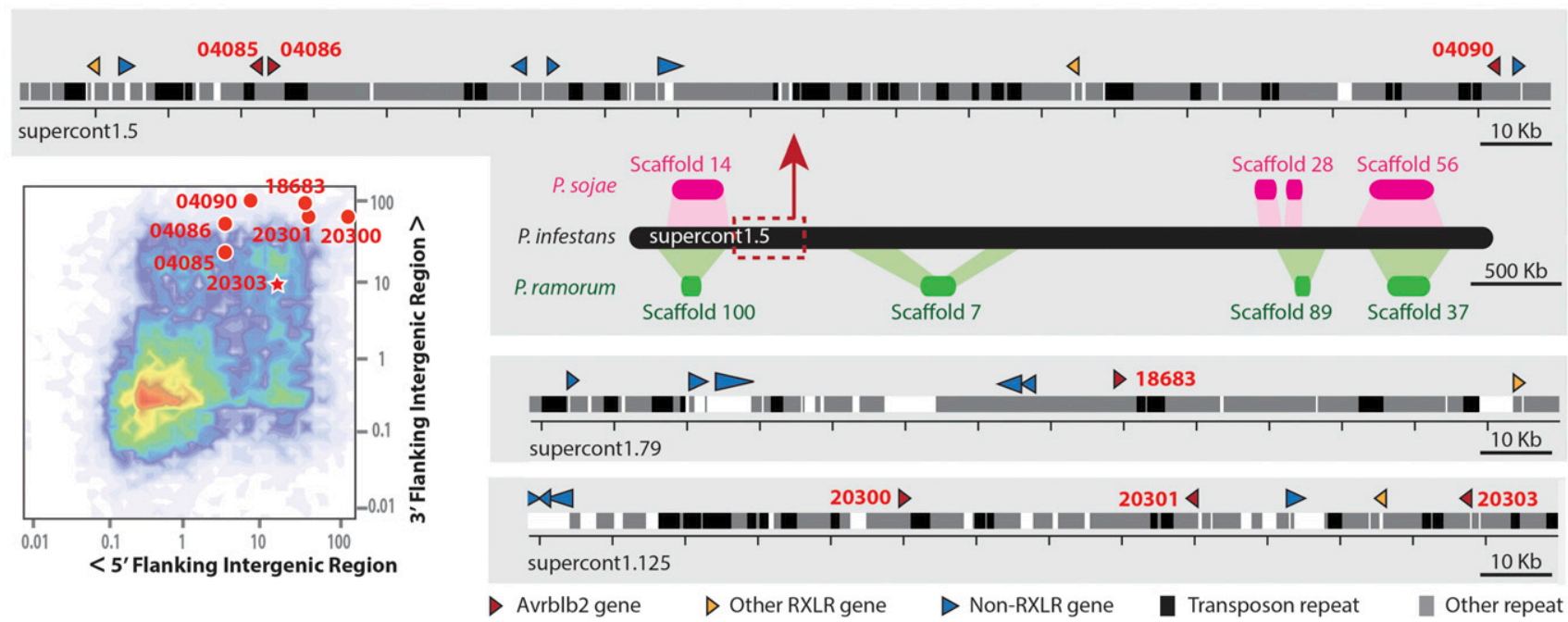

Fig. 1. Genome organization of Avrblb2 effector gene paralogs in Phytophthora infestans reference genome strain T30-4. A, Multiple sequence alignment of seven AVRblb2 effector paralogs present in P. infestans T30-4 genome. Single-letter amino acid codes were used. Residue numbers are denoted above the sequences. The predicted signal peptide, the RSLR motif, and amino acid positions 69, 70, 76, and 84 are indicated in colors. B, Left, distribution of Avrblb2 paralog genes within a 200-kb cross section of supercontigs 1.5, 1.79, and 1.125. Red box shows the location of Avrblb2 paralogs within supercontig 1.5 when aligned with $P$. sojae and $P$. ramorum scaffolds. Note that there is no synteny between $P$. infestans supercontigs 1.79 and 1.125 and $P$. sojae and $P$. ramorum genomes. Right, volcano plot shows that most Avrblb2 paralogs are located in the gene-sparse region of $P$. infestans genome based on their $5^{\prime}$ and $3^{\prime}$ flanking distances (>1.5 kb at either the $5^{\prime}$ or $3^{\prime}$ end). 
not be totally excluded. We failed to amplify additional Avrblb2 gene paralogs from $P$. mirabilis with primers designed in the flanking regions and, therefore, to link a particular identity to any of the Avrblb2 paralogs. We could not obtain amplification of PCR products for Avrblb2 or any of the gene paralogs in P. ipomoeae and $P$. phaseoli (Table 1). Taken together, these results indicate that Avrblb2 evolved in a basal branch of clade 1c spp. prior to the divergence of $P$. infestans, $P$. andina, and $P$. mirabilis.

\section{Expansion of Avrblb2 effector gene family predates the split between $P$. infestans and $P$. andina.}

Coalescence analysis traces all variants of a gene or group of genes to the most recent common ancestor, which is shared by the majority of the population (Hudson and Kaplan 1988; Tajima 1983). To investigate the molecular evolution and ancestry of Avrblb2, we constructed a gene genealogy of all available Avrblb2 sequences from Phytophthora clade 1c species. By combining our data with previously published Avrblb2 sequences (Oh et al. 2009), we generated a collection of 57 sequences, which represent at least 33 nonredundant nucleotide variants in $P$. infestans, $P$. andina, and $P$. mirabilis (Supplementary Table S4; Supplementary Fig. S1). Of the 33 variants differing in only one single amino acid change, two were from $P$. mirabilis. The rest of the Avrblb2 variants were from $P$. infestans $(n=25)$ and $P$. andina $(n=6)$. The coalescence analysis revealed a well-resolved genealogy with five major lineages, named Ala, Ile, Val, Phe, and Ala/Thr because they matched polymorphisms at residue 69 (Fig. 2). Four lineages were present in $P$. infestans (Ala, Val, Ile, and Phe) and $P$. andina (Ala, Val, Phe, and Ala/Thr); however, only one (Ala/Thr) included the $P$. mirabilis genes. These results indicate that the expansion in Avrblb2 paralogs observed in $P$. infestans and $P$. andina is relatively recent and has probably occurred following the split from P. mirabilis. In addition, multiple Avrblb2 gene duplication events have occurred prior to the split between $P$. infestans and $P$. andina, resulting in the distinct Avrblb2 lineages (Fig. 2).

\section{$P$. andina and $P$. mirabilis Avrblb2 effector homologs activate Rpi-blb2-mediated cell death.}

Infiltration of Nicotiana benthamiana leaves with mixtures of Agrobacterium tumefaciens strains expressing the Rpi-blb2 and AVRblb2 proteins results in a rapid cell death response $(\mathrm{Oh}$ et al. 2009). We took advantage of this assay to determine whether Avrblb2 homologs from $P$. andina and $P$. mirabilis activate Rpi-blb2-mediated cell death and, therefore, contribute to nonhost resistance of $S$. bulbocastanum to these species. Four Avrblb2 homologs were cloned into A. tumefaciens binary Potato virus $X$ (PVX) vector pGR106 (Huitema et al. 2004; Lu et al. 2003). Constructs pGR106-AA21 and pGR106-AB22 from $P$. andina and pGR106-AH27 from $P$. mirabilis were coinfiltrated in $N$. benthamiana leaves with and without the Rpi-blb2 resistance gene. The negative and positive controls were A. tumefaciens strains carrying pGR106-dGFP (dGFP) and pGR106-Avrblb2, respectively. Interestingly, we observed Rpi-blb2-dependent macroscopic cell death, visualized as autofluorescence in Figure 3, with $P$. andina variants $\mathrm{AA} 21$ and $\mathrm{AB} 22$ and $P$. mirabilis variant AH27 after 4 days postinoculation (dpi).

\section{Mutations at aa position 69 in AVRblb2 effector reveal that most residues do not alter recognition by Rpi-blb2.}

The positively selected residue 69 of AVRblb2 is the only polymorphic residue within the 34-aa avirulence-eliciting region that is crucial for Rpi-blb2 activation (Oh et al. 2009). Among the four natural substitutions previously reported, the Phe-69 mutant of AVRblb2 was significantly reduced in Rpi-blb2-mediated cell death compared with Ala-69, Val-69, and Ile-69 (Oh et al. 2009). To study the degree to which other amino acids at position 69 affect recognition by Rpi-blb2, we generated a mutant library of AVRblb2 using PCR-based random mutagenesis at position 69 (Bos et al. 2006). The mutants were cloned in the PVX binary expression vector pGR106, which allows sensitive and highthroughput in planta assays by wound inoculation (agroinfection) (Huitema et al. 2004). We then sequenced 96 random mutant clones and recovered 19 different AVRblb2 $2^{\mathrm{V} 69 \times}$ mutants. All selected mutants were identical to AVRblb2 ${ }^{\mathrm{V} 69}$ except for the 19 different residues at position 69. A premature stop codon-mutant (AVRblb2 ${ }^{\mathrm{V} 69 \text { stop }}$ ) was also recovered and used as a negative control. We used constructs dGFP and pGR106-INF1 as controls. $N$. benthamiana leaves, transiently expressing Rpi-blb2, were wound inoculated in triplicate with $A$. tumefaciens strains carrying the AVRblb2 mutant constructs. Cell-death responses surrounding the wounding sites, indicative of Rpi-blb2 hypersensitivity, were scored starting from $5 \mathrm{dpi}$. Seventeen of the mutants showed celldeath responses around the wounding site, indicating Rpi-blb2 hypersensitivity (Fig. 4). They developed consistent cell death responses ranging from 83 to $100 \%$ of the screened spots after 7 dpi. Only A. tumefaciens strains expressing pGR106AVRblb2 ${ }^{\text {V69Asp }}$ and pGR106-AVRblb2 ${ }^{\text {V69Phe }}$ consistently failed to induce Rpi-blb2-mediated cell death even after 10 dpi (Fig. 4).

Table 1. Loci and paralog-specific amplification of Avrblb2 effector homologs in Phytophthora clade 1c species

\begin{tabular}{|c|c|c|c|c|c|c|c|c|c|}
\hline \multirow[b]{3}{*}{ Phytophthora spp. } & \multirow[b]{3}{*}{ Strain } & \multirow[b]{3}{*}{ Origin $^{b}$} & \multirow[b]{3}{*}{ Loci $^{\mathrm{c}}$} & \multicolumn{6}{|c|}{ Paralog-specific (PITG) ${ }^{\mathbf{a}}$} \\
\hline & & & & 20300 & 20301 & 04090 & 18683 & 20303 & 04086 \\
\hline & & & & Ala69 & Phe69 & Ala69 & Ile69 & Phe69 & Ile69 \\
\hline P. infestans & T30-4 & NA & + & + & + & + & + & + & + \\
\hline P. infestans & 88069 & Netherlands & + & + & + & + & + & + & - \\
\hline P. infestans & $09-3925$ & Netherlands & + & - & - & + & - & - & + \\
\hline P. infestans & 90128 & Netherlands & + & - & - & + & - & - & + \\
\hline P. infestans & PIC99189 & Mexico & + & - & - & + & - & - & + \\
\hline P. infestans & Race-0 & Netherlands & + & + & + & + & + & + & + \\
\hline P. infestans & EC3843 & Ecuador & + & + & + & + & + & + & - \\
\hline P. infestans & IPO428 & Netherlands & + & + & - & + & - & - & - \\
\hline P. infestans & IPO566 & Netherlands & + & + & - & + & - & - & - \\
\hline P. andina & EC3425 & Ecuador & + & - & - & + & + & - & - \\
\hline$P$. andina & EC3644 & Ecuador & + & + & + & - & + & + & - \\
\hline$P$. andina & EC3163 & Ecuador & + & + & + & - & + & + & - \\
\hline P. mirabilis & PIC99114 & Mexico & + & - & - & - & - & - & - \\
\hline P. іротоеае & PIC99167 & Mexico & - & - & - & - & - & - & - \\
\hline P. phaseoli & RaceF18 & Mexico & - & - & - & - & - & - & - \\
\hline
\end{tabular}

${ }^{a}$ Presence or absence of each paralog-specific PITG.

b NA = not applied. T30-4 strain is an F1 of two aggressive strains of $P$. infestans originally isolated from potato in the Netherlands.

c Presence or absence of Avrblb2 effector amplicon using primers RD40F and RD40R described by Oh et al. (2009). 
These clones showed less than $16 \%$ of wounding sites with a cell death phenotype. The premature stop-codon mutant control of AVRblb2 (pGR106-AVRblb2 ${ }^{\mathrm{V} 69 \text { stop })}$ recorded no positive reaction. Altogether, these results showed that only a few residues at position 69 in AVRblb2 effector affect full activation of Rpi-blb2. One of these residues, Phe-69, is present in natural populations whereas Asp-69 has not been detected.

Polymorphism analyses of codon 69 in worldwide $P$. infestans populations indicates that all examined isolates carry multiple effector paralogs of Avrblb2.

To understand the diversity and distribution of Avrblb2 in populations of $P$. infestans and to determine the occurrence of predicted virulent phenotypes with only the Phe-69 paralog, we used a single-nucleotide polymorphism (SNP)-based approach to genotype the key codon 69 in the varying number of Avrblb2 paralogs. The sample includes 352 isolates collected from 14 different Solanum spp. and covers 23 potato-producing countries in Europe, South America, North America, and Asia (Supplementary Tables S5 and S6). Genotyping hundreds of strains with multiple and variable numbers of Avrblb2 copies is not as straightforward as it might initially seem and cannot be performed by classical amplicon sequencing due to the elevated number of closely related paralog sequences. We took advantage of the observation that the codons that determine the four naturally occurring amino acid 69 show the same nucleotide sequence in all $P$. infestans strains reported here or elsewhere (Oh et al. 2009). Therefore, we decided to target the first position of the triplet, SNP 205, as marker to estimate the complexity of the locus in the genome pool. To achieve this, we used

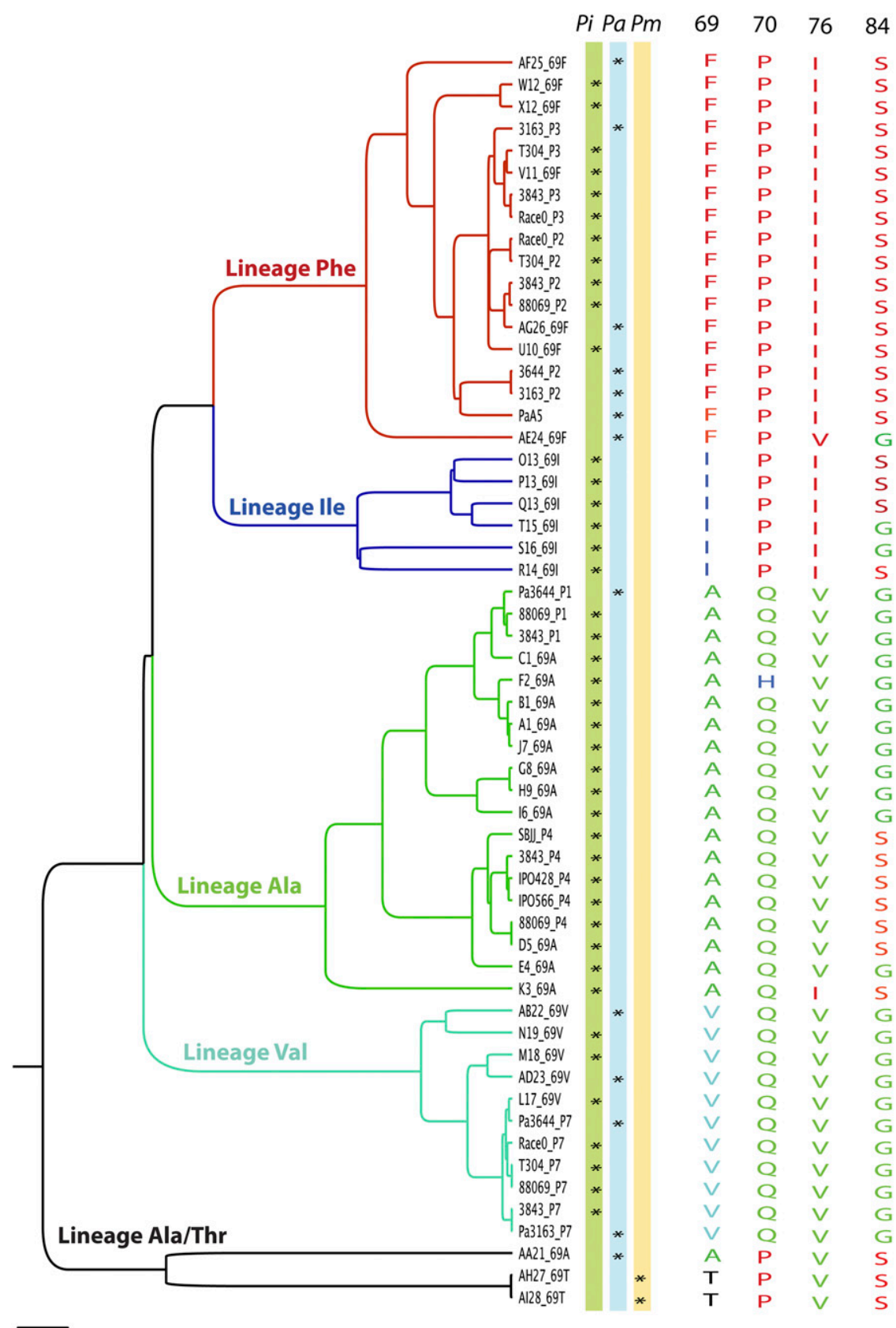

0.0030

Fig. 2. Coalescence analysis of AVRblb2 effector homologs revealed four major lineages in Phytophthora infestans and P. andina. Amino acid conformation of positions 69, 70, 76, and 84 located at the C-termini effector domain of AVRblb2 are detailed for all homologs that are present in the Phytophthora clade 1c sister species P. infestans $(\mathrm{Pi})$, P. andina $(\mathrm{Pa})$, and P. mirabilis $(\mathrm{Pm})$. Resulting lineages (Phe, Ile, Ala, Val and Ala/Thr) are uniquely associated with amino acid position 69. 
pyrosequencing to measure the proportion of each nucleotide at SNP 205. With this "sequencing-by-synthesis method", dNTPs are added sequentially. Upon nucleotide incorporation, the reaction generates a luminometric signal that is proportional to the number of nucleotides incorporated. We used this readout to calculate the relative proportion of dATP, dGTP, dTTP, and $\mathrm{dCTP}$ at nucleotide position 205 within the genome pool.

Based on pyrosequencing of SNP 205, we discovered that populations of $P$. infestans display complex configurations of the Avrblb2 loci (Fig. 5). This finding is consistent with multiple and variable number of paralogs in $P$. infestans genomes. Three (dATP, dGTP, and dTTP) of four possible nucleotides were detected at position 205 (Fig. 5A). We consistently found Avrblb2 SNP variants 205A (associated with Ile), 205G (associated with either Ala or Val), and 205T (associated with Phe) but none of the strains appear to have SNP 205C. However, none of the three variants was detected alone (at 100\% frequency) in any of the 352 genomes analyzed (Fig. 5A). Relative proportion of each SNP among genomes varied from 17 to $90 \%$ for $205 \mathrm{G}, 0$ to $83 \%$ for $205 \mathrm{~A}$, and 0 to $48 \%$ for $205 \mathrm{~T}$ (Fig. 5A). It is likely that the observed differences are due to variable numbers of copies among isolates. Interestingly, variant $205 \mathrm{G}$ was the only one that was present in all sampled isolates. Variants 205A and 205T were absent in 8.2 and $36.4 \%$ of the examined isolates, respectively (Fig. 5A).

Overall, we detected three different genotypes based on SNP 205 in the P. infestans metapopulation. The Avrblb2 genotype 205GAT was the most common, occurring in $55.4 \%$ of the isolates (Fig. 5B). This genotype occurred in isolates from Asia, Europe, and South and North America (Fig. 5C,). Isolates that harbor this particular SNP configuration were recovered from all host species within the sections Petota, Lycopersicon,

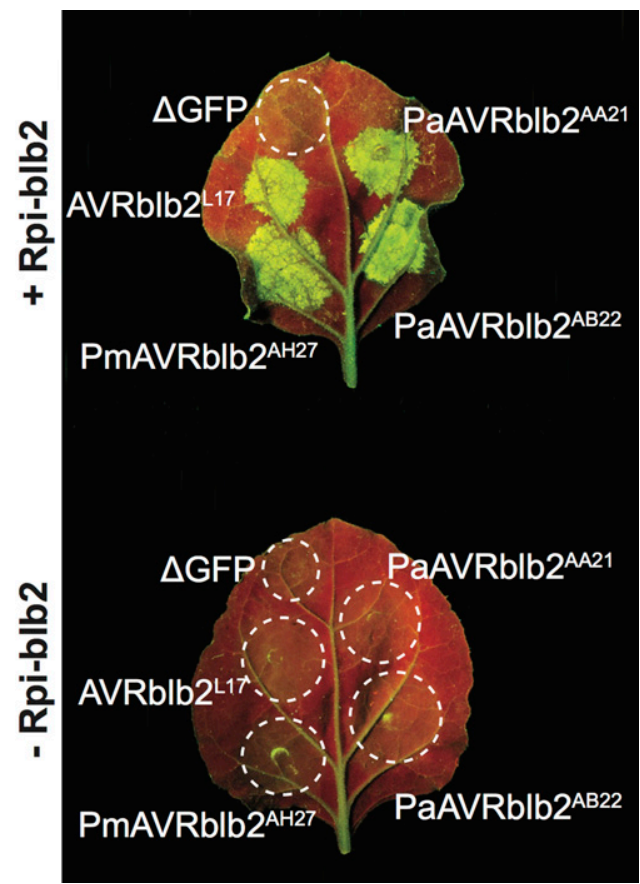

Fig. 3. AVRblb2 effector homologs from Phytophthora andina and $P$. mirabilis activate Rpi-blb2-mediated cell death. Hypersensitive response symptoms were observed in Nicotiana benthamiana leaves coexpressing Rpi-blb2 with different Avrblb2 homologous genes from, $P$. andina (PaAVRblb2 $2^{\mathrm{AA} 21}$ and PaAVRblb2 ${ }^{\mathrm{AB} 22}$ ), P. mirabilis (PmAVRblb2 ${ }^{\mathrm{AH} 27}$ ), and $P$. infestans (AVRblb2 ${ }^{\mathrm{L} 17}$ ) (upper panel). All effectors were expressed in the Potato mosaic virus (PVX)-based vector pGR106 and did not show auto-activity when expressed without Rpi-blb2 (lower panel). A truncated version of green fluorescent protein $(\Delta \mathrm{GFP})$ expressed in pGR106 was used as a negative control. The pictures were taken under UV light at 4 days post infiltration.
Juglandifolia, Basarthum, and Lasiocarpa (Fig. 5A and B). Other configurations were less frequent in the populations. Genotype $205 \mathrm{GA}$ occurs in $36.4 \%$ of the isolates whereas genotype 205GT was detected only in $8.2 \%$ (Fig. 5B). We detected genotype 205GA in all four geographical regions but we did not detect 205GT in South America (Fig. 5C). Taken together, the configuration and distribution of SNP 205 indicate that multiple gene copies of Avrblb2 are maintained in the genomes of $P$. infestans and in global populations of this pathogen.

To confirm the results and evaluate the robustness of this approach, we designed $3^{\prime}$ degenerated primers that specifically amplify each of the SNP variants. Using such allele-specific (AS)-PCR, we amplified a subsample of 100 P. infestans strains examined by pyrosequencing. We observed that 94 of 100 samples have the same genotypic designation after using both approaches. Potential PCR errors may have accounted for the observed difference between two methods.

\section{DISCUSSION}

The study of the P. infestans RXLR effector Avrblb2 is particularly timely and relevant because this effector is recognized by Rpi-blb2, a broad-spectrum resistance gene that is about to be deployed in agriculture (Oh et al. 2009; Vleeshouwers et al. 2008). Any insights into the genetic variation and structure of Avrblb2 in P. infestans populations should help evaluate the extent to which Rpi-blb2 has wide-spectrum activity against $P$. infestans. The knowledge we generated should also serve as a baseline to monitor the potential emergence of $P$. infestans races that overcome this $R$ gene; for example, by acquiring new Avrblb2 alleles or allele combinations. Here, we reconstructed the evolutionary history of Avrblb2 and characterized its genetic structure in global populations of $P$. infestans ( 352 isolates collected from 23 countries and 13 different hosts). Our data suggest that Avrblb2 first emerged as a single-copy gene in a putative ancestral species within Phytophthora clade 1c, followed by a recent expansion in the Phytophthora lineage that infects solanaceous hosts. As a consequence, at least four active variants of AVRblb2 occur in the late-blight pathogen $P$. infestans and there can be up to seven paralogs in a single isolate. Surprisingly, all Avrblb2 variants are maintained in $P$. infestans populations, suggesting a potential benefit for the

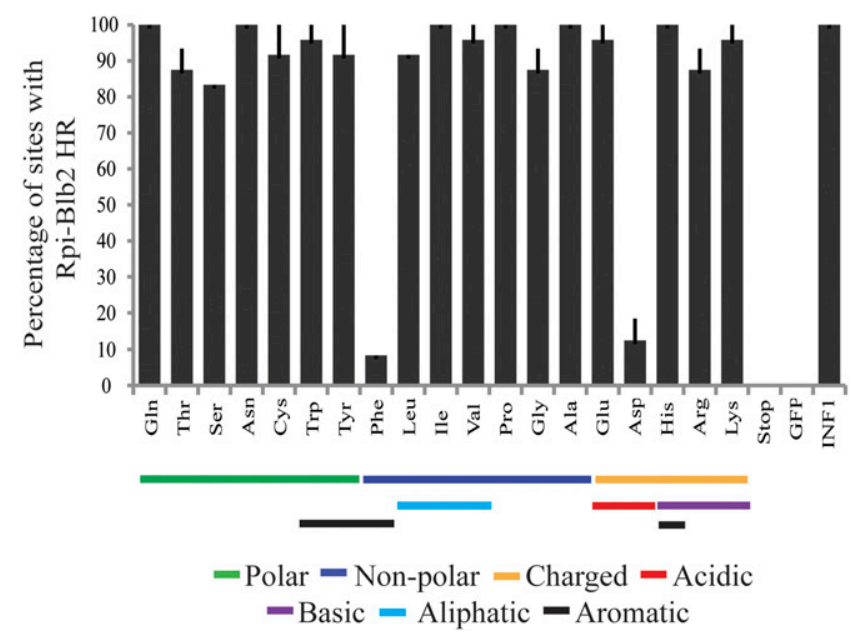

Fig. 4. Percentage of Rpi-blb2-mediated cell death induced by different AVRblb2 mutants at amino acid position 69 at 7 days post inoculation. Columns show the percentage of activation measured from 12 spots and error bars were calculated from two independent experiments. HR = hypersensitive response. Biochemical properties of each amino acid are shown in color. 
pathogen to preserve duplicated versions of quasi-identical (>90\%) Avrblb2 genes.

Our results indicate that duplicated Avrblb2 paralogs evolved relatively recently within the $P$. infestans lineage, given that it occurs as a single gene in the sister taxon $P$. mirabilis, which is estimated to have diverged from $P$. infestans approximately 1,300 years ago (Yoshida et al. 2013). What are the reasons behind the expansion of Avrblb2 into multiple copies in $P$. infestans? One possibility is that a dosage effect affected the paralogous copies of Avrblb2 during adaptation of $P$. infestans to Solanum hosts. Gene duplications are thought to be beneficial in eukaryotic and prokaryotic genes that mediate interaction with the environment (Kondrashov and Kondrashov 2006; Kondrashov et al. 2002; Romero and Palacios 1997). A causative effect between gene dosage and adaptation has been observed in almost all taxa: prokaryotes, plants, mammals, fungi, protists, and so on (Kondrashov et al. 2002). An increase in dosage may be positively selected if increased levels of the effector protein enhance the pathogen success. Under this model, it is conceivable that different environments could select for different copy numbers during the evolution of sister taxa. The relevance of the occurrence of multiple copies of effector genes and their impact on the phenotype is difficult to address experimentally. However, we could assume that the increase in Avrblb2 paralogs has affected fitness because both gene expansions and copy number variation (tandemly duplicated gene copies) are common in oomycete and fungal plant pathogens (Dong et al. 2009; Jiang et al. 2006; Qutob et al. 2006, 2009; Raffaele and Kamoun 2012; Ridout et al. 2006). Perhaps the most dramatic example of an effector gene amplification is the case of Avh426 in the soybean pathogen P. sojae, with approximately 54 nearly identical predicted gene copies.

Even though a dosage effect could account for the increased number of Avrblb2 paralogs in P. infestans, additional factors may underpin the evolutionary arms race between the pathogen and its hosts. Similar to the Hyaloperonospora arabidopsidis RXLR effector ATR13 (Allen et al. 2004, 2008) and Melampsora lini
AvrL567 (Dodds et al. 2004, 2006), AVRblb2 displays high levels of polymorphism (Oh et al. 2009). Furthermore, none of the observed mutations in the $P$. infestans Avrblb2 paralogs resulted in pseudogenization. This suggests that, despite the duplications, AVRblb2 virulence function is likely to be preserved while a high level of amino acid change is retained. In addition to the increasing number of polymorphic sites, coalescence analysis recognized four ancestral lineages. One possible explanation is that purifying selection reduced lineage diversity after multiple duplication events. Interestingly, all four lineages were consistently found in pathogen populations over a broad range of geographic origins or host preferences. All these observations are in concordance with balancing selection, maintaining the four major forms of AVRblb2 within $P$. infestans populations, probably because they contribute to dual effector functions as discussed below.

Elicitation of host defense and promotion of virulence are two distinct activities of host-translocated RXLR effector proteins with opposite effects on pathogen fitness (Bos et al. 2006, 2009; Win et al. 2012a). We hypothesize that one or both of these activities is responsible for maintaining distinct AVRblb2 variants by balancing selection. Effector diversity could be correlated with $R$ gene diversity in other oomycetes effectors, such as H. arabidopsidis ATR13 (Hall et al. 2009) and P. infestans PiAVR2 (Champouret 2010). In both of these cases, different alleles of the corresponding immune receptor, Arabidopsis RPP13 or Solanum R2, can recognize ATR13 or PiAVR2 effector variants, respectively. $R$ gene diversification related to effector evolution is expected to be driven by arms race coevolution. This model becomes quite convincing for the R2-PiAVR2 pair because recognition of PiAVR2 was only observed in Solanum spp. originating from Mexico (Champouret 2010), the proposed center of coevolution between Solanum and $P$. infestans (Grünwald and Flier 2005). In the case of AVRblb2, the maintenance of the four major 69 variants may reflect recognition by different $R$ genes. Although additional $R$ genes that respond to AVRblb2 have not been described to date, Vleeshouwers et al.
A

Frequency of nucleotides at SNP205 of Avrblb2 in $P$. infestans population :

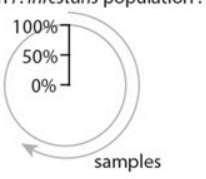

samples

Nucleotide type:

G A T
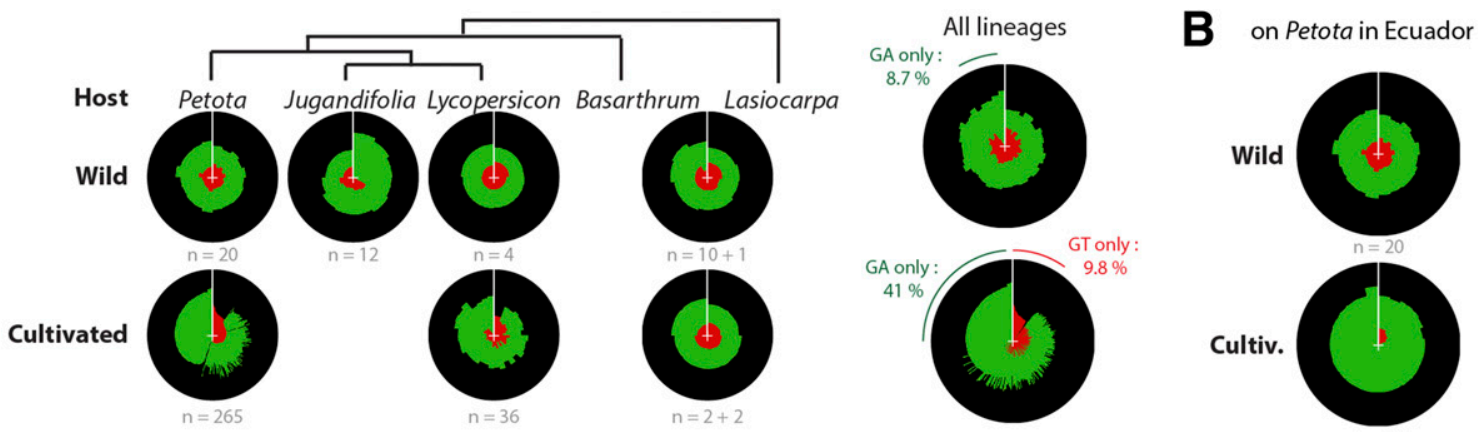

C Proportion of genotypes in sample per geographic area

$0 /$ no data

50 100
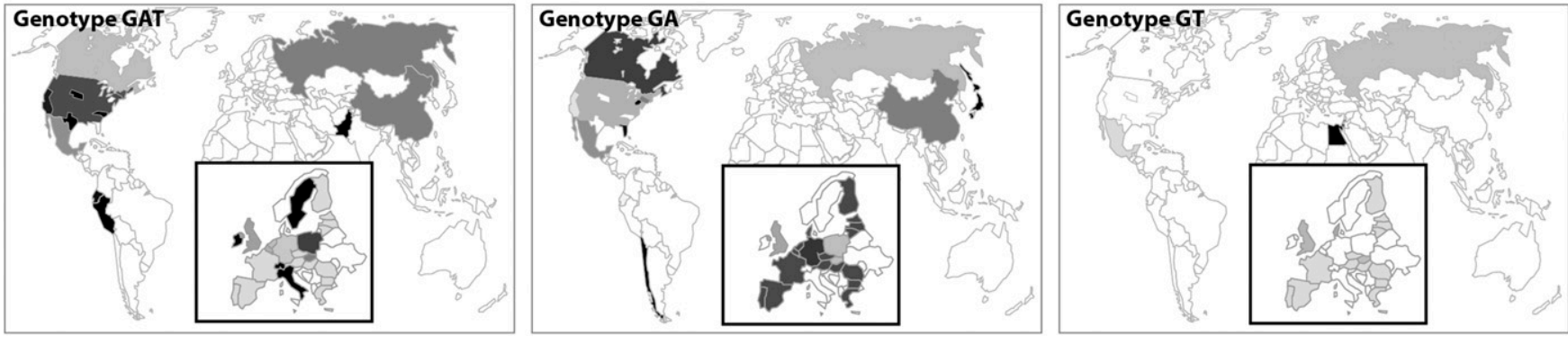

Fig. 5. Avrblb2 effector gene paralogs are maintained in global Phytophthora infestans populations. Distribution of Avrblb2 variants based on the relative amount of single-nucleotide polymorphism (SNP) 205. A, Relative proportion of SNP 205G, 205A, and 205T in the genome pool among individuals of P. infestans from wild and cultivated Solanum host from the sections Basarthum, Lasiocarpa, Juglandifolia, Lycopersicon, and Petota (Bohs 2005). B, Overall and C, per-country distribution of genotype 205 in the P. infestans population from Asia, Europe, North America, and South America. 
(2008) detected Rpi-blb2-like activities in several Solanum spp. unrelated to $S$. bulbocastanum. This could explain why $P$. andina, a hybrid that does not occur in Mexico, also carries a high number of Avrblb2 variants.

Another scenario is that the multiple copies of Avrblb2 are related to the virulence activity of this effector and are maintained to match diversity in effector targets within host Solanum spp. We know little about how oomycete effectors manipulate plant processes inside host cells, in contrast to apoplastic effectors that are known to inhibit plant defense enzymes (Dong et al. 2014; Kaschani et al. 2010; Song et al. 2009; Tian et al. 2004; van der Hoorn et al. 2010). Bos et al. (2010) showed that the RXLR effector AVR3a of $P$. infestans manipulates host immunity by stabilizing the E3 ligase CMPG1. Recently, AVRblb2 was shown to enhance susceptibility to $P$. infestans when ectopically expressed in plants, and progress has been achieved in understanding how this effector alters host immunity (Bozkurt et al. 2011). It turned out that AVRblb2 focally accumulates around haustoria to prevent the secretion into the apoplast of $\mathrm{C} 14$, a papain-like cysteine protease with a positive role in plant immunity (Bozkurt et al. 2011). Thus, it is possible that Avrblb2 diversification was driven by interaction with a polymorphic protease or even with different proteases of the Solanum hosts of $P$. infestans. In line with this interpretation, Kaschani et al. (2010) recently discovered six new $\mathrm{C} 14$ protease alleles in the wild potato species $S$. demissum, $S$. verrucosum, and $S$. stoliniferum that are the natural hosts of $P$. infestans in central Mexico. Interestingly, C14 proteases are under diversifying selection in these wild potato species but not in tomato. We do not know whether different AVRblb2 variants interact specifically with $\mathrm{C} 14$ alleles but the work of Kaschani et al. (2010) suggests that the hosts may maintain a diverse set of rapidly evolving targets. In conclusion, $R$ genes, or virulence targets, or even both classes of molecules have probably shaped Avrblb2 genetic diversity.

Recently, the role of gene duplication in evolution was determined to be more complex and potent than previously thought (Näsvall et al. 2012; Pennisi 2012). Näsvall et al. (2012) proposed and experimentally validated the innovation-amplificationdivergence (IAD) model as a mechanism to enable the rapid emergence of new gene functions. The IAD model is based on the observation that many proteins are promiscuous, carrying minor side activities that could become beneficial under particular environmental conditions (innovation) (Näsvall et al. 2012). Therefore, gene duplication (amplification) facilitates rapid optimization of such side activities, eventually resulting in a new gene function (divergence). IAD is particularly relevant to pathogen effectors, given that they are often promiscuous, with a single effector interacting with multiple plant proteins and affecting distinct host processes (Hogenhout et al. 2009; Win et al. 2012a). AVRblb2 (PexRD40 170-7) associates and interferes with the secretion of a plant immune protease, $\mathrm{C} 14$, but was also shown to interact with four other plant proteins (Bozkurt et al. 2011). It will be relevant to determine the degree to which the AVRblb2 variants have additional or different host targets and virulence activities compared with PexRD40 $170-7$.

To date, only one class of naturally occurring variants of AVRblb2 was found to evade recognition by Rpi-blb2. All these variants carry Phe at position 69 (Oh et al. 2009) (Fig. 4). In the screen described in Figure 4, we only identified an additional amino acid at position 69, Asp, to impair activation of Rpi-blb2. Whether this mutation would arise in natural populations of $P$. infestans following the deployment of Rpi-blb2 in agriculture is unclear and will depend on the degree to which Asp-69 affects AVRblb2 stability and its effect on the virulence activities of this effector.

We still do not understand the mechanistic basis of nonhost resistance to oomycete pathogens. Chaparro-Garcia et al.
(2011) reported that nonhost resistance to $P$. mirabilis involves additional defense layers to basal resistance. Their conclusion is based on the finding that silencing the gene encoding the modulator of surface immunity SERK3 (also known as BAK1) in $N$. benthamiana dramatically enhanced susceptibility to compatible $P$. infestans strains but did not affect the nonhost interaction between this plant and $P$. mirabilis. Also, it has been proposed that NB-LRR immune receptors can contribute to nonhost resistance to fungi in Arabidopsis and barley (Jafary et al. 2006; Lipka et al. 2008). However, the extent to which ETI contributes to NB-LRR-mediated nonhost resistance to oomycetes remains unclear. Here, we found that the $S$. bulbocastanum Rpi-blb2 immune receptor recognizes the single-copy AVRblb2 gene present in $P$. mirabilis and we hypothesize that Rpi-blb2 could contribute to nonhost resistance of Solanum spp. to P. mirabilis.

Broad-spectrum late-blight $R$ genes are useful for deployment in agriculture, especially when stacked, and promise to deliver a sustainable genetic solution to the management of this devastating disease (Jo et al. 2014; Vleeshouwers et al. 2011; Zhu et al. 2012). Recently, Tan et al. (2010) showed an additive effect in late-blight resistance levels when pyramiding Rpi-mcdl and Rpi-ber. The combination of Rpi-blb1 and Rpi-blb2 is expected to maximize the potential for durability because both genes protect against a diverse set of $P$. infestans strains (Song et al. 2003; van der Vossen et al. 2003, 2005). Indeed, a potato variety that carries both genes has been developed. The deployment of this or similar potato varieties will inform whether such a strategy is effective. In this study, we used an effectorbased approach to study the genetic composition of Avrblb2 in the $P$. infestans metapopulation and obtain a snapshot of current populations that should prove useful for future studies. This strategy can also be used as a screening tool to monitor in situ locally adapted pathogen populations upon deployment, as proposed previously by Vleeshouwers et al. (2011) and Li et al. (2012). The expansion of the Avrblb2 gene family during the evolution of $P$. infestans points to an important contribution to pathogen fitness on solanaceous hosts. Assuming that Avrblb2 dosage or multiple copies are essential for full pathogen fitness, it seems possible that consecutive point mutations or deletions would achieve a gain of virulence. Nonetheless, other mechanisms such as epigenetic gene silencing of the effector gene or Rpi-blb2 suppression by a different effector may emerge in virulent races, and the potential for $P$. infestans to overcome $R$ genes remains at the same time formidable and unpredictable.

\section{MATERIALS AND METHODS}

\section{Microbial strains, plant, and culture conditions.}

$P$. infestans samples used in this study were obtained from different sources, including the World Phytophthora Collection, Plant Research International, BASF, The Sainsbury Laboratory, James Hutton Institute, and International Potato Center (Supplementary Table S7). We analyzed a total of 352 DNA samples collected in 23 different countries. The collection includes isolates from Asia, Europe, South America, and North America. Samples were collected from 14 different hosts among five Solanum sections. DNA samples of $P$. andina, $P$. mirabilis, $P$. ipomoeae, and $P$. phaseoli were also used in this study. $N$. benthamiana and potato (S. tuberosum) plants were grown and maintained at 22 to $25^{\circ} \mathrm{C}$ in a controlled greenhouse under a photoperiod of 16 and $8 \mathrm{~h}$ of light and darkness, respectively. A. tumefaciens GV3101 (Hellens et al. 2000) was routinely grown in Luria-Bertani (LB) media (Sambrook and Russel 2001) with appropriate antibiotics at $28^{\circ} \mathrm{C}$. All bacterial DNA transformations were conducted by electroporation using standard protocols (Sambrook and Russel 2001). 


\section{Amplification, cloning, and sequence}

\section{of Avrblb2 effector gene homologs and paralogs.}

We amplified Avrblb2 from P. infestans isolates using highfidelity Phusion polymerase (New England Biolabs, Beverly, MA, U.S.A.). To target the mature protein, we used PCR conditions and primers RD40-F and RD40-R, previously described by $\mathrm{Oh}$ et al. (2009) and included in Supplementary Table S1. Avrblb2 homologs from $P$. andina and $P$. mirabilis isolates were synthesized by Genewiz Inc. Amplicons were cloned into the pGEM-T vector following the manufacturer's instructions (Promega Corp.) or into the ClaI and NotI sites of the binary PVX vector pGR106 (Lu et al. 2003).

Independent clones were sequenced using the same oligonucleotide combination. Reactions were performed with BigDye 3.1 (Applied Biosystems, Palo Alto, CA, U.S.A.) following the manufacturer's instructions. Sequencing took place at The Genome Analysis Centre in Norwich, U.K. Bioinformatics analyses were performed locally on Mac OSX workstations using standard bioinformatics programs such as BLAST 2.2.11 (Altschul et al. 1997), ClustalW (Chenna et al. 2003), and Sequencher 4.8 (Gene Codes, Ann Arbor, MI, U.S.A.). Multiple alignments were conducted using MUSCLE (Edgar 2004). For the Avrblb2 polymorphism analysis, only sequences with phred Q values higher than 20 were retained. Sequences were aligned, and ambiguous calls were checked against chromatograms using Sequencher 4.8 (Gene Codes).

To determine paralog identity, the sequence of Avrblb2 (Oh et al. 2009) was searched against the T30-4 P. infestans genome browser (Broad Institute) (Haas et al. 2009). Seven predicted coding genes (PITG) were retrieved with a cutoff e- 45 and $\geq 90 \%$ similarity to Avrblb2. The specific PITG identifiers were PITG_04090, PITG_04085, PITG_04086, PITG_18683, PITG_20300, PITG_20301, and PITG_20303. Primers used to amplify each of the seven Avrblb2 paralogs were designed within $1 \mathrm{~kb}$ of the $5^{\prime}$ and $3^{\prime}$ flanking regions. Primer candidates were searched against the T30-4 P. infestans genome browser to assess specificity. PCR amplifications of each gene were performed using GoTaq (Promega Corp.). The set of primers is described in Supplementary Table S1. Approximately $100 \mathrm{ng}$ of DNA was included in a $25-\mu \mathrm{l}$ reaction mixture together with $1 \times$ reaction buffer (Promega Corp.), $100 \mu \mathrm{M}$ each dNTP (New England BioLabs), $0.3 \mu \mathrm{M}$ each primer (MWGBIOTECH, Ebersberg, Germany), and $1.5 \mathrm{mM} \mathrm{MgCl} 2$. Cycling conditions were $95^{\circ} \mathrm{C}$ for $2 \mathrm{~min}$; followed by 30 cycles of $95^{\circ} \mathrm{C}$ for $45 \mathrm{~s}, 61^{\circ} \mathrm{C}$ for $30 \mathrm{~s}$, and $72^{\circ} \mathrm{C}$ for $60 \mathrm{~s}$; and a final extension step of $72^{\circ} \mathrm{C}$ for $20 \mathrm{~min}$. Fragments were resolved in $1 \%$ agar gels. A subset of bands was excised and purified using a Qiagen kit (Valencia, CA, U.S.A.) and sequenced directly.

\section{Coalescence analysis of Avrblb2 gene family.}

Coalescent analysis was carried out on the subset of 57 Avrblb2 sequences from this study. Nucleotide sequences were aligned using MUSCLE (Edgar 2004). Coalescent analysis was done with the BEAST package (Drummond et al. 2002), version 1.4.8, using 10 million generations, optimizing models toward basal representation of the $P$. mirabilis, which is known to be basal to $P$. andina and $P$. infestans (Blair et al. 2008). A strict molecular clock was used. Priors were kept to standard settings. The first $10 \%$ of the trees sampled (trees from the first 1 million generations) were discarded, corresponding trace files were inspected, and all had reached the stationary phase. Effective sample size values were above 200. The tree shown in Figure 2 was created from the resulting trees using the module TreeAnnotator of this package and is the maximum clade credibility tree of the analysis, with target heights kept.

\section{Targeted mutagenesis of amino acid position 69 at the C-termini effector domain of Avrblb2.}

Site-directed mutants of position 69 were generated by overlap extension PCR using high-fidelity Pfu polymerase
(Stratagene, La Jolla, CA, U.S.A.), as described previously (Bos et al. 2009). The first PCR amplification was performed with primers PVX_FLAG-F and [NNNN-R]. A second PCR amplification was performed using primers RD40 - $\mathrm{R}$ and [NNNN-F]. A third and final PCR amplification was performed on a 1:1 mix of the amplicons generated by the first and second PCR amplifications, using primers PVX_FLAG-F and RD40-R. Amplicons were ligated into the $\bar{C} l a \mathrm{I}-$ and NotI-digested pGR106 vector and were transformed into A. tumefaciens, as explained above. A 96-well plate of random colonies was sequenced and a set of 19 different substitutions at amino acid position 69 was identified. A stop-codon mutant was also included for further experiments.

\section{Plant assays: Agroinfiltration and agroinfection.}

Agroinfiltration (A. tumefaciens transient transformation assay) and agroinfection (A. tumefaciens/PVX-mediated transformation) experiments were performed on 4- to 6-week-old $N$. benthamiana plants using previously described methods (Huitema et al. 2004; Torto et al. 2003; van der Hoorn et al. 2000). For agroinfiltration assays, recombinant $A$. tumefaciens strains were grown as described elsewhere (van der Hoorn et al. 2000), except that culturing steps were performed in LB media supplemented with kanamycin at $50 \mathrm{mg} / \mathrm{ml}$ (Sambrook and Russel 2001). The cells were collected by centrifugation $(5,000 \times g$, $5 \mathrm{~min}$ ) and resuspended in inducing media $\left(10 \mathrm{mM} \mathrm{MgCl}_{2}\right.$, $10 \mathrm{mM}$ morpholinoethanesulfonic acid [MES] [pH 5.6], and $200 \mathrm{mM}$ acetosyringone) until a final optical density at $600 \mathrm{~nm}$ $\left(\mathrm{OD}_{600}\right)$ of 0.2 . To test the avirulence activity of the AVRblb2 homologs, A. tumefaciens strains carrying the pBINplus-Rpi-blb2 (Oh et al. 2009) were mixed in a 1:1 ratio with pGR106Avrblb2 ${ }^{\mathrm{L} 17}$, pGR106-AB22, pGR106-AA21, and pGR106-AH27. As a negative control for the PVX assays, we used the dGFP construct carrying a truncated and reversed fragment of the green fluorescent protein (GFP) gene ( $\Delta$ GFP) (Bos et al. 2006). All clones were agroinfiltrated into eight different leaves, and the experiment was repeated twice.

For the functional screens of the AVRblb2 mutants, leaves of $N$. benthamiana were infiltrated with $A$. tumefaciens carrying the pBINplus-Rpi-blb2 construct (Oh et al. 2009) until an $\mathrm{OD}_{600}$ of 0.3 in induction buffer $\left(10 \mathrm{mM} \mathrm{MgCl}_{2}, 10 \mathrm{mM}\right.$ MES [pH 5.6], and $200 \mathrm{mM}$ acetosyringone). One day after infiltration, leaves were challenged by wound inoculation of AVRblb2 mutant clones using toothpicks. Each mutant was assayed in three independent spots on four replicated leaves. As a control, each leaf was wound inoculated with $A$. tumefaciens strains carrying pGR106-INF1 and dGFP. Cell-death symptoms at the inoculation site were scored 7 to 10 dpi. The experiment was repeated twice.

\section{Genotyping SNP 205 of Avrblb2 effector gene in a $P$. infestans metapopulation.}

To determine the composition of SNP 205 and to allow discrimination of different Avrblb2 genotypes in a P. infestans metapopulation, we used a sequencing-by-synthesis (pyrosequencing) method. The primer Pryro-F and the biotinylated primer PyroBio-R were used to amplify a 100-bp region (position 48 to 78 ) within the C-terminal part of Avrblb2 paralogs. Fragment size was confirmed on $2 \%$ agarose gels. Samples were prepared for analysis as recommended by the manufacturer's instructions (Biotage AB, Uppsala, Sweden). PCR product $(40 \mu \mathrm{l})$ was immobilized to Streptavidin-coated sheparose bits ( $3 \mu \mathrm{l}$ per sample) buy incubating in $1 \times$ binding buffer ( $37 \mu \mathrm{l}$ per sample) for $10 \mathrm{~min}$ at room temperature. Beads were treated for $5 \mathrm{~s}$ with $70 \%$ ethanol, denaturation buffer, and washing buffer. Each solution was removed successively using a vacuum tool. Beads were transfer to a PSQ 96-well plate (Qiagen) containing $40 \mu \mathrm{l}$ of annealing buffer and $0.4 \mu \mathrm{M}$ primer DYY_endGTA, DYY_endATA, and DYY_endGTT. After 
hitting the plate at $80^{\circ} \mathrm{C}$ for $5 \mathrm{~min}$, primer annealing occurred during cooling at room temperature. Nucleotide incorporation of SNP 205 was measured on a PSQ 96MA instrument (Qiagen) using PSQ reagents according to standard protocols (Qiagen). Order of dispensation was as follow: CTAGCTCATGA. Data scores are given as the concentration (in percentage) of all different variants in the sample. Each 96-well plate contained different control samples, including clone pGR106Avrblb2 ${ }^{\text {Phe69 }}$, pGR106-Avrblb2 ${ }^{\text {Val69, }}$, pR106-Avrblb2 ${ }^{\text {Ile69 }}$ (Oh et al. 2009), P. infestans T30-4, and a water sample.

To test the robustness of the pyrosequencing approach, an AS-PCR amplification method was also used (Wu et al. 1989). Three degenerated reverse primers (t69-R-ASPCR, g69-RASPCR, and a69-R-ASPCR) and one general forward primer (x69-F-ASPCR) were designed to increase primer specificity for SNP variants 205T, 205G, and 205A. Primers have one specific mutation on the 3 'end followed by a second mismatch mutation two to three nucleotides before to avoid amplification of unspecific products. The PCR amplification cycling program and gel resolution were as reported above, with minor modifications. Reaction mix contained $1 \mathrm{mM} \mathrm{MgCl} 2$ and annealing temperature was $63^{\circ} \mathrm{C}$. In total, 100 strain samples were tested together with control samples.

\section{ACKNOWLEDGMENTS}

We thank G. J. T. Kessel, G. Forbes, D. E. L. Cooke, and M. D. Coffey for providing Phytophthora infestans isolates. This research was supported by BASF Plant Science and The Gatsby Charitable Foundation.

\section{LITERATURE CITED}

Allen, R. L., Bittner-Eddy, P. D., Grenville-Briggs, L. J., Meitz, J. C., Rehmany, A. P., Rose, L. E., and Beynon, J. L. 2004. Host-parasite coevolutionary conflict between Arabidopsis and downy mildew. Science 306:1957-1960.

Allen, R. L., Meitz, J. C., Baumber, R. E., Hall, S. A., Lee, S. C., Rose, L. E., and Beynon, J. L. 2008. Natural variation reveals key amino acids in a downy mildew effector that alters recognition specificity by an Arabidopsis resistance gene. Mol. Plant Pathol. 9:511-523.

Altschul, S. F., Madden, T. L., Schaffer, A. A., Zhang, J., Zhang, Z., Miller, W., and Lipman, D. J. 1997. Gapped BLAST and PSI-BLAST: A new generation of protein database search programs. Nucleic Acids Res. 25: 3389-3402.

Armstrong, M. R., Whisson, S. C., Pritchard, L., Bos, J. I. B., Venter, E., Avrova, A. O., Rehmany, A. P., Böhme, U., Brooks, K., Cherevach, I., Hamlin, N., White, B., Fraser, A., Lord, A., Quail, M. A., Churcher, C., Hall, N., Berriman, M., Huang, S., Kamoun, S., Beynon, J. L., and Birch, P. R. J. 2005. An ancestral oomycete locus contains late blight avirulence gene Avr3a, encoding a protein that is recognized in the host cytoplasm. Proc. Natl. Acad. Sci. U.S.A. 102:7766-7771.

Ballvora, A., Ercolano, M. R., Weiss, J., Meksem, K., Bormann, C. A., Oberhagemann, P., Salamini, F., and Gebhardt, C. 2002. The R1 gene for potato resistance to late blight (Phytophthora infestans) belongs to the leucine zipper/NBS/LRR class of plant resistance genes. Plant J. 30: 361-371.

Blair, J. E., Coffey, M. D., Park, S. Y., Geiser, D. M., and Kang, S. 2008. A multi-locus phylogeny for Phytophthora utilizing markers derived from complete genome sequences. Fungal Genet. Biol. 45:266-277.

Bohs, L. 2005. Major clades in Solanum based on $n d h F$ sequence data. Pages 27-49 in: A festschrift for William G. D'Arcy: The legacy of a taxonomist. R. C. Keating, V. C. Hollowell, and T. B. Croat, eds. Missouri Botanical Garden Press, St. Louis.

Bos, J. I. B., Armstrong, M. R., Gilroy, E. M., Boevink, P. C., Hein, I., Taylor, R. M., Zhendong, T., Engelhardt, S., Vetukuri, R. R., Harrower, B., Dixelius, C., Bryan, G., Sadanandom, A., Whisson, S. C., Kamoun, S., and Birch, P. R. J. 2010. Phytophthora infestans effector AVR3a is essential for virulence and manipulates plant immunity by stabilizing host E3 ligase CMPG1. Proc. Natl. Acad. Sci. U.S.A. 107:9909-9914.

Bos, J. I. B., Chaparro-Garcia, A., Quesada-Ocampo, L. M., McSpadden Gardener, B. B., and Kamoun, S. 2009. Distinct amino acids of the Phytophthora infestans effector AVR3a condition activation of R3a hypersensitivity and suppression of cell death. Mol. Plant-Microbe Interact. 22:269-281.
Bos, J. I. B., Kanneganti, T. D., Young, C., Cakir, C., Huitema, E., Win, J., Armstrong, M. R., Birch, P. R., and Kamoun, S. 2006. The C-terminal half of Phytophthora infestans RXLR effector AVR3a is sufficient to trigger R3a-mediated hypersensitivity and suppress INF1-induced cell death in Nicotiana benthamiana. Plant J. 48:165-176.

Boutemy, L. S., King, S. R. F., Win, J., Hughes, R. K., Clarke, T. A., Blumenschein, T. M. A., Kamoun, S., and Banfield, M. J. 2011. Structures of Phytophthora RXLR effector proteins: A conserved but adaptable fold underpins functional diversity. J. Biol. Chem. 286: 35834-35842.

Bozkurt, T. O., Schornack, S., Win, J., Shindo, T., Ilyas, M., Oliva, R., Cano, L. M., Jones, A. M., Huitema, E., van der Hoorn, R. A., and Kamoun, S. 2011. Phytophthora infestans effector AVRblb2 prevents secretion of a plant immune protease at the haustorial interface. Proc. Natl. Acad. Sci. U.S.A. 108:20832-20837.

Champouret, N. 2010. Pages 43-90 in: Functional Genomics of Phytophthora infestans Effectors and Solanum Resistance Genes. R. G. F. Visser and E. Jacobsen, eds. Department of Plant Breeding. Wageningen University UR, Wageningen, The Netherlands.

Champouret, N., Bouwmeester, K., Rietman, H., van der Lee, T., Maliepaard, C., Heupink, A., van de Vondervoort, P. J., Jacobsen, E., Visser, R. G., van der Vossen, E. A., Govers, F., and Vleeshouwers, V. G. 2009. Phytophthora infestans isolates lacking class I ipiO variants are virulent on Rpi-blb1 potato. Mol. Plant-Microbe Interact. 22:1535-1545.

Chaparro-Garcia, A., Wilkinson, R. C., Gimenez-Ibanez, S., Findlay, K., Coffey, M. D., Zipfel, C., Rathjen, J. P., Kamoun, S., and Schornack, S. 2011. The receptor-like kinase SERK3/BAK1 is required for basal resistance against the late blight pathogen Phytophthora infestans in Nicotiana benthamiana. PLoS One 6:e16608.

Chen, Y., Liu, Z., and Halterman, D. A. 2012. Molecular determinants of resistance activation and suppression by Phytophthora infestans effector IPI-O. PLoS Pathog. 8:e1002595.

Chenna, R., Sugawara, H., Koike, T., Lopez, R., Gibson, T. J., Higgins, D. G., and Thompson, J. D. 2003. Multiple sequence alignment with the Clustal series of programs. Nucleic Acids Res. 31:3497-3500.

Croll, D., and McDonald, B. A. 2012. The accessory genome as a cradle for adaptive evolution in pathogens. PLoS Pathog. 8:e1002608.

Dodds, P. N., Lawrence, G. J., Catanzariti, A. M., Ayliffe, M. A., and Ellis, J. G. 2004. The Melampsora lini AvrL567 avirulence genes are expressed in haustoria and their products are recognized inside plant cells. Plant Cell 16:755-768.

Dodds, P. N., Lawrence, G. J., Catanzariti, A. M., Teh, T., Wang, C. I., Ayliffe, M. A., Kobe, B., and Ellis, J. G. 2006. Direct protein interaction underlies gene-for-gene specificity and coevolution of the flax resistance genes and flax rust avirulence genes. Proc. Natl. Acad. Sci. U.S.A. 103: 8888-8893.

Dong, S., Qutob, D., Tedman-Jones, J., Kuflu, K., Wang, Y., Tyler, B. M., and Gijzen, M. 2009. The Phytophthora sojae avirulence locus Avr3c encodes a multi-copy RXLR effector with sequence polymorphisms among pathogen strains. PLoS One 4:e5556.

Dong, S., Stam, R., Cano, L. M., Song, J., Sklenar, J., Yoshida, K., Bozkurt, T. O., Oliva, R., Liu, Z., Tian, M., Win, J., Banfield, M. J., Jones, A. M., van der Hoorn, R. A., and Kamoun, S. 2014. Effector specialization in a lineage of the Irish potato famine pathogen. Science 343:552-555.

Drummond, A. J., Nicholls, G. K., Rodrigo, A. G., and Solomon, W. 2002. Estimating mutation parameters, population history and genealogy simultaneously from temporally spaced sequence data. Genetics 161 : 1307-1320.

Edgar, R. C. 2004. MUSCLE: Multiple sequence alignment with high accuracy and high throughput. Nucleic Acids Res. 32:1792-1797.

Foster, S. J., Park, T. H., Pel, M., Brigneti, G., Sliwka, J., Jagger, L., van der Vossen, E., and Jones, J. D. G. 2009. Rpi-vnt1.1, a Tm-2(2) homolog from Solanum venturii, confers resistance to potato late blight. Mol. Plant-Microbe Interact. 22:589-600.

Fry, W. 2008. Phytophthora infestans: The plant (and $R$ gene) destroyer. Mol. Plant Pathol. 9:385-402.

Gilroy, E. M., Breen, S., Whisson, S. C., Squires, J., Hein, I., Kaczmarek, M., Turnbull, D., Boevink, P. C., Lokossou, A., Cano, L. M., Morales, J., Avrova, A. O., Pritchard, L., Randall, E., Lees, A., Govers, F., van West, P., Kamoun, S., Vleeshouwers, V. G., Cooke, D. E., and Birch, P. R. 2011. Presence/absence, differential expression and sequence polymorphisms between PiAVR2 and PiAVR2-like in Phytophthora infestans determine virulence on R2 plants. New Phytol. 191:763-776.

Goss, E. M., Cardenas, M. E., Myers, K., Forbes, G. A., Fry, W. E., Restrepo, S., and Grünwald, N. J. 2011. The plant pathogen Phytophthora andina emerged via hybridization of an unknown Phytophthora species and the Irish potato famine pathogen, P. infestans. PLoS One 6:e24543. 
Goss, E. M., Tabima, J. F., Cooke, D. E., Restrepo, S., Fry, W. E., Forbes, G. A., Fieland, V. J., Cardenas, M., and Grünwald, N. J. 2014. The Irish potato famine pathogen Phytophthora infestans originated in central Mexico rather than the Andes. Proc. Natl. Acad. Sci. U.S.A. 111: 8791-8796.

Grünwald, N. J., and Flier, W. G. 2005. The biology of Phytophthora infestans at its center of origin. Annu. Rev. Phytopathol. 43:171-190.

Haas, B. J., Kamoun, S., Zody, M. C., Jiang, R. H., Handsaker, R. E., Cano, L. M., Grabherr, M., Kodira, C. D., Raffaele, S., Torto-Alalibo, T., Bozkurt, T. O., Ah-Fong, A. M., Alvarado, L., Anderson, V. L., Armstrong, M. R., Avrova, A., Baxter, L., Beynon, J., Boevink, P. C., Bollmann, S. R., Bos, J. I., Bulone, V., Cai, G., Cakir, C., Carrington, J. C., Chawner, M., Conti, L., Costanzo, S., Ewan, R., Fahlgren, N. Fischbach, M. A., Fugelstad, J., Gilroy, E. M., Gnerre, S., Green, P. J., Grenville-Briggs, L. J., Griffith, J., Grünwald, N. J., Horn, K., Horner, N. R., Hu, C. H., Huitema, E., Jeong, D. H., Jones, A. M., Jones, J. D., Jones, R. W., Karlsson, E. K., Kunjeti, S. G., Lamour, K., Liu, Z., Ma, L., Maclean, D., Chibucos, M. C., McDonald, H., McWalters, J., Meijer, H. J., Morgan, W., Morris, P. F., Munro, C. A., O’Neill, K., OspinaGiraldo, M., Pinzón, A., Pritchard, L., Ramsahoye, B., Ren, Q. Restrepo, S., Roy, S., Sadanandom, A., Savidor, A., Schornack, S., Schwartz, D. C., Schumann, U. D., Schwessinger, B., Seyer, L., Sharpe, T., Silvar, C., Song, J., Studholme, D. J., Sykes, S., Thines, M., van de Vondervoort, P. J., Phuntumart, V., Wawra, S., Weide, R., Win, J., Young, C., Zhou, S., Fry, W., Meyers, B. C., van West, P., Ristaino, J., Govers, F., Birch, P. R., Whisson, S. C., Judelson, H. S., and Nusbaum, C. 2009. Genome sequence and analysis of the Irish potato famine pathogen Phytophthora infestans. Nature 461:393-398.

Hall, S. A., Allen, R. L., Baumber, R. E., Baxter, L. A., Fisher, K., BittnerEddy, P. D., Rose, L. E., Holub, E. B., and Beynon, J. L. 2009. Maintenance of genetic variation in plants and pathogens involves complex networks of gene-for-gene interactions. Mol. Plant Pathol. 10: 449-457.

Hellens, R., Mullineaux, P., and Klee, H. 2000. Technical focus: A guide to Agrobacterium binary Ti vectors. Trends Plant Sci. 5:446-451.

Hogenhout, S. A., van der Hoorn, R. A., Terauchi, R., and Kamoun, S. 2009. Emerging concepts in effector biology of plant-associated organisms. Mol. Plant-Microbe Interact. 22:115-122.

Huang, S., Vleeshouwers, V. G. A. A., Visser, R. G. F., and Jacobsen, E. 2005. An accurate in vitro assay for high-throughput disease testing of Phytophthora infestans in potato. Plant Dis. 89:1263-1267.

Hudson, R. R., and Kaplan, N. L. 1988. The coalescent process in models with selection and recombination. Genetics 120:831-840.

Huitema, E., Bos, J. I., Tian, M., Win, J., Waugh, M. E., and Kamoun, S. 2004. Linking sequence to phenotype in Phytophthora-plant interactions. Trends Microbiol. 12:193-200.

Jacob, F., Vernaldi, S., and Maekawa, T. 2013. Evolution and conservation of plant NLR functions. Front. Immunol. 4:297.

Jafary, H., Szabo, L. J., and Niks, R. E. 2006. Innate nonhost immunity in barley to different heterologous rust fungi is controlled by sets of resistance genes with different and overlapping specificities. Mol. PlantMicrobe Interact. 19:1270-1279.

Jiang, R. H., Tyler, B. M., and Govers, F. 2006. Comparative analysis of Phytophthora genes encoding secreted proteins reveals conserved synteny and lineage-specific gene duplications and deletions. Mol. Plant-Microbe Interact. 19:1311-1321.

Jo, K. R., Kim, C. J., Kim, S. J., Kim, T. Y., Bergervoet, M., Jongsma, M. A., Visser, R. G., Jacobsen, E., and Vossen, J. H. 2014. Development of late blight resistant potatoes by cisgene stacking. BMC Biotechnol. 14:50.

Jones, J. D., and Dangl, J. L. 2006. The plant immune system. Nature 444: 323-329.

Kamoun, S. 2003. Molecular genetics of pathogenic oomycetes. Eukaryot. Cell 2:191-199.

Kamoun, S., Furzer, O., Jones, J. D., Judelson, H. S., Ali, G. S., Dalio, R. J., Roy, S. G., Schena, L., Zambounis, A., Panabières, F., Cahill, D., Ruocco, M., Figueiredo, A., Chen, X. R., Hulvey, J., Stam, R., Lamour, K., Gijzen, M., Tyler, B. M., Grünwald, N. J., Mukhtar, M. S., Tomé, D. F., Tör, M., Van Den Ackerveken, G., McDowell, J., Daayf, F., Fry, W. E., Lindqvist-Kreuze, H., Meijer, H. J., Petre, B., Ristaino, J., Yoshida, K., Birch, P. R., and Govers, F. 2015. The Top 10 oomycete pathogens in molecular plant pathology. Mol. Plant Pathol. 16:413-434.

Kaschani, F., Shabab, M., Bozkurt, T., Shindo, T., Schornack, S., Gu, C., Ilyas, M., Win, J., Kamoun, S., and van der Hoorn, R. A. 2010. An effector-targeted protease contributes to defense against Phytophthora infestans and is under diversifying selection in natural hosts. Plant Physiol. 154:1794-1804.

Kondrashov, F. A., and Kondrashov, A. S. 2006. Role of selection in fixation of gene duplications. J. Theor. Biol. 239:141-151.
Kondrashov, F. A., Rogozin, I. B., Wolf, Y. I., and Koonin, E. V. 2002. Selection in the evolution of gene duplications. Online publication. Genome Biol. 3:RESEARCH0008.

Li, G., Huang, S., Guo, X., Li, Y., Yang, Y., Guo, Z., Kuang, H., Rietman, H., Bergervoet, M., Vleeshouwers, V. G., van der Vossen, E. A. G., Qu, D., Visser, R. G. F., Jacobsen, E., and Vossen, J. H. 2011. Cloning and characterization of $\mathrm{r} 3 \mathrm{~b}$; members of the $\mathrm{r} 3$ superfamily of late blight resistance genes show sequence and functional divergence. Mol. PlantMicrobe Interact. 24:1132-1142.

Li, Y., van der Lee, T. A., Evenhuis, A., van den Bosch, G. B., van Bekkum, P. J., Forch, M. G., van Gent-Pelzer, M. P., van Raaij, H. M., Jacobsen, E., Huang, S. W., Govers, F., Vleeshouwers, V. G., and Kessel, G. J 2012. Population dynamics of Phytophthora infestans in the Netherlands reveals expansion and spread of dominant clonal lineages and virulence in sexual offspring. G3 2:1529-1540.

Lipka, U., Fuchs, R., and Lipka, V. 2008. Arabidopsis non-host resistance to powdery mildews. Curr. Opin. Plant Biol. 11:404-411.

Lokossou, A. A., Park, T. H., van Arkel, G., Arens, M., Ruyter-Spira, C., Morales, J., Whisson, S. C., Birch, P. R. J., Visser, R. G. F., Jacobsen, E., and van der Vossen, E. A. G. 2009. Exploiting knowledge of $R / A v r$ genes to rapidly clone a new LZ-NBS-LRR family of late blight resistance genes from potato linkage group IV. Mol. Plant-Microbe Interact. 22: 630-641.

Lu, R., Malcuit, I., Moffett, P., Ruiz, M. T., Peart, J., Wu, A. J., Rathjen, J. P., Bendahmane, A., Day, L., and Baulcombe, D. C. 2003. High throughput virus-induced gene silencing implicates heat shock protein 90 in plant disease resistance. EMBO J. 22:5690-5699.

Martin, F. N., Blair, J. E., and Coffey, M. D. 2014. A combined mitochondrial and nuclear multilocus phylogeny of the genus Phytophthora. Fungal Genet. Biol. 66:19-32.

McDonald, B. A., and Linde, C. 2002. Pathogen population genetics, evolutionary potential, and durable resistance. Annu. Rev. Phytopathol 40:349-379.

Morgan, W., and Kamoun, S. 2007. RXLR effectors of plant pathogenic oomycetes. Curr. Opin. Microbiol. 10:332-338.

Mukhtar, M. S. 2013. Engineering NLR immune receptors for broadspectrum disease resistance. Trends Plant Sci. 18:469-472.

Näsvall, J., Sun, L., Roth, J. R., and Andersson, D. I. 2012. Real-time evolution of new genes by innovation, amplification, and divergence. Science 338:384-387.

Oh, S. K., Young, C., Lee, M., Oliva, R., Bozkurt, T. O., Cano, L. M., Win, J., Bos, J. I., Liu, H. Y., van Damme, M., Morgan, W., Choi, D., Van der Vossen, E. A., Vleeshouwers, V. G., and Kamoun, S. 2009. In planta expression screens of Phytophthora infestans RXLR effectors reveal diverse phenotypes, including activation of the Solanum bulbocastanum disease resistance protein Rpi-blb2. Plant Cell 21:2928-2947.

Park, T. H., Vleeshouwers, V. G. A. A., Jacobsen, E., van der Vossen, E., and Visser, R. G. F. 2009. Molecular breeding for resistance to Phytophthora infestans (Mont.) de Bary in potato (Solanum tuberosum L.): A perspective of cisgenesis. Plant Breed. 128:109-117.

Pel, M. A. 2010. Mapping, isolation and characterization of genes responsible for late blight resistance in potato. Wageningen University, The Netherlands.

Pennisi, E. 2012. Evolution. Gene duplication's role in evolution gets richer, more complex. Science 338:316-317.

Qutob, D., Tedman-Jones, J., Dong, S., Kuflu, K., Pham, H., Wang, Y., Dou, D., Kale, S. D., Arredondo, F. D., Tyler, B. M., and Gijzen, M. 2009 Copy number variation and transcriptional polymorphisms of Phytophthora sojae RXLR effector genes Avrla and Avr3a. PLoS One 4:e5066.

Qutob, D., Tedman-Jones, J., and Gijzen, M. 2006. Effector-triggered immunity by the plant pathogen Phytophthora. Trends Microbiol. 14:470-473.

Raffaele, S., Farrer, R. A., Cano, L. M., Studholme, D. J., MacLean, D., Thines, M., Jiang, R. H., Zody, M. C., Kunjeti, S. G., Donofrio, N. M., Meyers, B. C., Nusbaum, C., and Kamoun, S. 2010. Genome evolution following host jumps in the Irish potato famine pathogen lineage. Science 330:1540-1543.

Raffaele, S., and Kamoun, S. 2012. Genome evolution in filamentous plant pathogens: Why bigger can be better. Nat. Rev. Microbiol. 10: 417-430.

Ridout, C. J., Skamnioti, P., Porritt, O., Sacristan, S., Jones, J. D., and Brown, J. K. 2006. Multiple avirulence paralogues in cereal powdery mildew fungi may contribute to parasite fitness and defeat of plant resistance. Plant Cell 18:2402-2414.

Rietman, H., Bijsterbosch, G., Cano, L. M., Lee, H. R., Vossen, J. H., Jacobsen, E., Visser, R. G., Kamoun, S., and Vleeshouwers, V. G. 2012 Qualitative and quantitative late blight resistance in the potato cultivar Sarpo Mira is determined by the perception of five distinct RXLR effectors. Mol. Plant-Microbe Interact. 25:910-919. 
Romero, D., and Palacios, R. 1997. Gene amplification and genomic plasticity in prokaryotes. Annu. Rev. Genet. 31:91-111.

Sambrook, J., and Russel, D. 2001. Molecular Cloning: A Laboratory Manual. Cold Spring Harbor Laboratory Press, Cold Spring Harbor, NY, U.S.A.

Song, J., Bradeen, J. M., Naess, S. K., Raasch, J. A., Wielgus, S. M., Haberlach, G. T., Liu, J., Kuang, H., Austin-Phillips, S., Buell, C. R., Helgeson, J. P., and Jiang, J. 2003. Gene RB cloned from Solanum bulbocastanum confers broad spectrum resistance to potato late blight. Proc. Natl. Acad. Sci. U.S.A. 100:9128-9133.

Song, J., Win, J., Tian, M., Schornack, S., Kaschani, F., Ilyas, M., van der Hoorn, R. A., and Kamoun, S. 2009. Apoplastic effectors secreted by two unrelated eukaryotic plant pathogens target the tomato defense protease Rcr3. Proc. Natl. Acad. Sci. U.S.A. 106:1654-1659.

Tajima, F. 1983. Evolutionary relationship of DNA sequences in finite populations. Genetics 105:437-460.

Takken, F., and Rep, M. 2010. The arms race between tomato and Fusarium oxysporum. Mol. Plant Pathol. 11:309-314.

Tan, M. Y., Hutten, R. C., Visser, R. G., and van Eck, H. J. 2010. The effect of pyramiding Phytophthora infestans resistance genes $R \mathrm{Pi}$-mcdl and $R$ Pi-ber in potato. Theor. Appl. Genet. 121:117-125.

Tian, M., Huitema, E., Da Cunha, L., Torto-Alalibo, T., and Kamoun, S. 2004. A Kazal-like extracellular serine protease inhibitor from Phytophthora infestans targets the tomato pathogenesis-related protease P69B. J. Biol. Chem. 279:26370-26377.

Torto, T. A., Li, S., Styer, A., Huitema, E., Testa, A., Gow, N. A., van West, P., and Kamoun, S. 2003. EST mining and functional expression assays identify extracellular effector proteins from the plant pathogen Phytophthora. Genome Res. 13:1675-1685.

Tyler, B. M., Tripathy, S., Zhang, X., Dehal, P., Jiang, R. H. Y., Aerts, A., Arredondo, F. D., Baxter, L., Bensasson, D., Beynon, J. L., Chapman, J., Damasceno, C. M. B., Dorrance, A. E., Dou, D., Dickerman, A. W., Dubchak, I. L., Garbelotto, M., Gijzen, M., Gordon, S. G., Govers, F., Grünwald, N. J., Huang, W., Ivors, K. L., Jones, R. W., Kamoun, S., Krampis, K., Lamour, K. H., Lee, M. K., McDonald, W. H., Medina, M., Meijer, H. J. G., Nordberg, E. K., Maclean, D. J., Ospina-Giraldo, M. D., Morris, P. F., Phuntumart, V., Putnam, N. H., Rash, S., Rose, J. K. C., Sakihama, Y., Salamov, A. A., Savidor, A., Scheuring, C. F., Smith, B. M., Sobral, B. W. S., Terry, A., Torto-Alalibo, T. A., Win, J., Xu, Z., Zhang, H., Grigoriev, I. V., Rokhsar, D. S., and Boore, J. L. 2006. Phytophthora genome sequences uncover evolutionary origins and mechanisms of pathogenesis. Science 313:1261-1266.

van der Hoorn, R. A. L., Gu, C., Ilyas, M., Kolodziejek, I., Kumari, S., MisasVillamil, J. C., Pruzinska, A., Richau, K. H., Shabab, M., Shindo, T., Wang, Z., and Kaschani, F. 2010. Mining the active proteome in plant-pathogen interactions. In: Biology of Plant-Microbe Interactions. T. A. H. Antound, L. Brisson, D. Prevost, and M. Trepanier, eds. International Society for Molecular Plant-Microbe Interactions, St. Paul, MN, U.S.A.

van der Hoorn, R. A. L., and Kamoun, S. 2008. From guard to decoy: A new model for perception of plant pathogen effectors. Plant Cell 20: 2009-2017.

van der Hoorn, R. A. L., Laurent, F., Roth, R., and De Wit, P. J. G. M. 2000. Agroinfiltration is a versatile tool that facilitates comparative analyses of Avr9/Cf-9-induced and Avr4/Cf-4-induced necrosis. Mol. Plant-Microbe Interact. 13:439-446. van der Vossen, E., Sikkema, A., Hekkert, B. t. L., Gros, J., Stevens, P., Muskens, M., Wouters, D., Pereira, A., Stiekema, W., and Allefs, S. 2003. An ancient $R$ gene from the wild potato species Solanum bulbocastanum confers broad-spectrum resistance to Phytophthora infestans in cultivated potato and tomato. Plant J. 36:867-882.

van der Vossen, E. A., Gros, J., Sikkema, A., Muskens, M., Wouters, D., Wolters, P., Pereira, A., and Allefs, S. 2005. The Rpi-blb2 gene from Solanum bulbocastanum is an $\mathrm{Mi}-1$ gene homolog conferring broadspectrum late blight resistance in potato. Plant J. 44:208-222.

van Poppel, P. M., Guo, J., van de Vondervoort, P. J., Jung, M. W., Birch, P. R., Whisson, S. C., and Govers, F. 2008. The Phytophthora infestans avirulence gene Avr4 encodes an RXLR-dEER effector. Mol. PlantMicrobe Interact. 21:1460-1470.

Vleeshouwers, V. G., Raffaele, S., Vossen, J. H., Champouret, N., Oliva, R., Segretin, M. E., Rietman, H., Cano, L. M., Lokossou, A., Kessel, G., Pel, M. A., and Kamoun, S. 2011. Understanding and exploiting late blight resistance in the age of effectors. Annu. Rev. Phytopathol. 49:507-531.

Vleeshouwers, V. G., Rietman, H., Krenek, P., Champouret, N., Young, C., Oh, S. K., Wang, M., Bouwmeester, K., Vosman, B., Visser, R. G., Jacobsen, E., Govers, F., Kamoun, S., and Van der Vossen, E. A. 2008. Effector genomics accelerates discovery and functional profiling of potato disease resistance and Phytophthora infestans avirulence genes. PLoS One 3:e2875.

Win, J., Chaparro-Garcia, A., Belhaj, K., Saunders, D. G., Yoshida, K., Dong, S., Schornack, S., Zipfel, C., Robatzek, S., Hogenhout, S. A., and Kamoun, S. 2012a. Effector biology of plant-associated organisms: Concepts and perspectives. Cold Spring Harb. Symp. Quant. Biol. 77:235-247.

Win, J., Krasileva, K. V., Kamoun, S., Shirasu, K., Staskawicz, B. J., and Banfield, M. J. 2012b. Sequence divergent RXLR effectors share a structural fold conserved across plant pathogenic oomycete species. PLoS Pathog. 8:e1002400.

Wu, D. Y., Ugozzoli, L., Pal, B. K., and Wallace, R. B. 1989. Allele-specific enzymatic amplication of beta-globin genomic DNA for diagnosis of sickle cell anemia. Proc. Natl. Acad. Sci. U.S.A. 86:2757-2760.

Yoshida, K., Schuenemann, V. J., Cano, L. M., Pais, M., Mishra, B., Sharma, R., Lanz, C., Martin, F. N., Kamoun, S., Krause, J., Thines, M., Weigel, D., and Burbano, H. A. 2013. The rise and fall of the Phytophthora infestans lineage that triggered the Irish potato famine. eLife 2:e00731.

Zhu, S., Li, Y., Vossen, J. H., Visser, R. G., and Jacobsen, E. 2012. Functional stacking of three resistance genes against Phytophthora infestans in potato. Transgenic Res. 21:89-99.

\section{AUTHOR-RECOMMENDED INTERNET RESOURCES}

Broad Institute: www.broadinstitute.org

Genewiz Inc.: www.genewiz.com

Kamoun Lab web page: http://www.KamounLab.net

NCBI Genome Project for Phytophthora infestans: http://www.ncbi.nlm.nih.gov/genome/genomes/293

Phytophthora infestans Database at Broad Institute: http://www. broadinstitute.org/annotation/genome/phytophthora_infestans/MultiHome. html

Video: Agroinfiltration of the wild tobacco plant Nicotiana benthamiana: http://youtu.be/GHc7PU_jG2M 